\title{
Ultimate pretreatment of lignocellulose in bioethanol production by combining both acidic and alkaline pretreatment
}

\author{
Dinh Quan Nguyen ${ }^{1, *}$, Le Nhat Minh Nguyen $^{1}$, Thi Tuong An Tran ${ }^{1}$, Hoai Nhan Cao ${ }^{1}$, Thi Kim Phung Le ${ }^{1}$, and \\ Thanh Phong Mai ${ }^{1}$ \\ ${ }^{1}$ Laboratory of Biofuel and Biomass Research, Vietnam National University of Ho Chi Minh City, University of Technology, 268 Ly \\ Thuong Kiet st. ward 14, district 10, Ho Chi Minh City, S. R. Vietnam
}

\begin{abstract}
Alkaline pretreatment has been known as the most popular method to process lignocellulosic materials for bioethanol production due to its simplicity and high efficiency. However, the waste water of the process has a very high basicity, which requires neutralization with acids upon further disposal. In this study, rubber wood saw dust (Hevea brasiliensis) was employed as lignocellulosic material and its pretreatment was inspected with both diluted $\mathrm{H}_{2} \mathrm{SO}_{4}$ and $\mathrm{NaOH}$ in different combination ways. Hereby, acid was used not only for waste water neutralization but also to contribute to lignin removal. Analysis results showed that an aqueous solution of $2.0-2.5 \mathrm{wt} . \% \mathrm{H}_{2} \mathrm{SO}_{4}$ can be used to treat the biomass followed by alkaline pretreatment. By this so-called combo-pretreatment technique, cellulose was well preserved without significant hydrolysis while the final pretreatment efficiency was up to $63.0 \%$, compared to $48.2 \%$ of using only the alkaline solution and $13.7 \%$ of using only the acidic solution. Finally, alkaline waste water can be mixed to be neutralized with acidic waste water from the two previous steps. This innovated technique improved the pretreatment efficiency almost without increasing in chemical cost.
\end{abstract}

\section{Introduction}

Global energy demand is increasing while the major environmental damage is caused by the combustion of fossil fuel. Therefore, renewable resources have been the vital trend of the world development. Among them, lignocellulosic biomass is popular, abundant and able to be utilized from agricultural wastes. More specifically, lignocellulose-based bioethanol, as known as the $2^{\text {nd }}$ generation bioethanol, attracts a lot of interest from both academic and industrial fields $[1,2]$.

To produce bioethanol from lignocellulose materials, it usually needs pretreatment and hydrolysis to convert cellulose into glucose. Lignocellulose materials have very strong structures, mainly consisted of lignin, hemicellulose, and cellulose. The purpose of the pretreatment is to remove lignin and hemicellulose, reduce cellulose crystallinity, and increase the porosity of the materials. Physical, physico- chemical, chemical, and biological processes have been used for pretreatment of lignocellulosic materials. There have been many previous studies of lignocellulose pretreatment, including:

- Mechanical methods: grinding, steam explosion, applying high pressure steam [3-5].

- Chemical methods: soaking the materials in alkaline or acidic solution, organic solvents; oxidants or reducing agents; surfactants [6-8].

- Biological method [9-10]
- Combining steam explosion, mechanical grinding with alkaline or acid [11]

Among the methods above, alkaline or acidic pretreatments have been known as the most popular method due to their simplicity and high efficiency. After this type of pretreatment, the waste water solution needs to be neutralized for further disposal because it still contains much either alkaline or acid. Obviously, the remaining chemicals can be quite reused or utilized as mentioned previously [1]. In this study, a combination pretreatment of both lignocellulosic rubber saw dust by both acid and alkaline is carried out. Hereby, instead of using $\mathrm{H}_{2} \mathrm{SO}_{4}$ acid to only neutralize the wasted alkaline solution of alkaline pretreatment, the dilute acidic solution is also used to pretreat the lignocellulose in order to increase the pretreatment efficiency while not increasing the total cost of chemicals.

\section{Materials and methods}

\subsection{Material}

Wood saw dust of Hevea brasilensis was obtained from Binh Duong province, Vietnam. The wood was screened to achieve appropriate particle sizes of $0.16 \mathrm{~mm}$ to $1.5 \mathrm{~mm}$. The wood was then dried to reduce moisture content lower than $15.0 \mathrm{wt} \%$ and stored at room temperature. The dry lignocellulose content was

* Corresponding author: ndquan@ @cmut.edu.vn 
determined by oven drying at $105^{\circ} \mathrm{C}$ until constant weight as described elsewhere [12].

\subsection{Analytical methods}

\subsubsection{Ash content}

Using a crucible and muffle furnace, the ash content of a sample is analyzed with a ramping program for $6 \mathrm{~h}$ until constant weight as described in literature [13].

Calculation:

$$
\% \text { Ash }=\frac{\text { Weight }_{\text {crucible }+ \text { ash }}-\text { Weight }_{\text {crucible }}}{O D W_{\text {sample }}} \times 100
$$

\subsubsection{Lignin content}

Lignin content of the lignocellulosic samples was analyzed following the standard method presented by the National Renewable Energy Laboratory (NREL, Denver, CO, USA) [14].

The amount of acid-soluble lignin [ASL] was determined by UV/vis spectroscopy at 240nm. The amount of acid-insoluble lignin [AIL] was determined by drying the acid-treated samples at $105^{\circ} \mathrm{C}$, then burning at $575^{\circ} \mathrm{C}$ for $24 \mathrm{~h}$. Total lignin content of the samples was calculated as followings:

$$
\begin{aligned}
& \% A I L=\frac{\left(\text { Weight }_{\text {cuniblete ALL }}-\text { Weight }_{\text {cucible }}\right)-\left(\text { Weight }_{\text {cunciblet As }}-\text { Weight }_{\text {cncible }}\right)}{\text { ODW }} \times 100 \\
& \% A S L=\frac{U V_{\text {abs }} \times \text { Volume }_{\text {filtrate }} \times \text { Dilution }}{\varepsilon \times O D W_{\text {sample }} \times \text { Pathlengh }} \times 100
\end{aligned}
$$

where UVabs = average UV-Vis absorbance at $240 \mathrm{~nm}$, $\varepsilon=$ Absorptivity of bxiomass at specific wavelength $(=25)$.

\subsubsection{Cellulose content}

The cellulose content of lignocellulose samples was analyzed by Anthrone method [15]. This method is based on the colorimetric reaction between cellulose and anthrone. The color intensity of the sample is proportional to the cellulose concentration in a determined wavelength.

The cellulose content was measured by hydrolyzing the polysaccharides into simple sugars by acid hydrolysis, estimating the resultant monosaccharides and determined by UV/vis spectroscopy at $630 \mathrm{~nm}$. With the optical density (OD), calculate the amount of cellulose based on the standard curve of cellulose.

Calculation:

$$
\% \text { cell }=\frac{x_{(\mathrm{mg} / \mathrm{ml})} \times \text { Volume }_{\text {acid }- \text { treated }- \text { sample }}}{\text { ODW }} \times 100
$$

where: $\mathrm{x}=$ amount of cellulose content $(\mathrm{mg} / \mathrm{ml})$

\subsection{Acidic and alkaline pretreatment}

5 grams of saw dust (dry basis) was soaked in aqueous solution of acid $\left(\mathrm{H}_{2} \mathrm{SO}_{4}\right)$ or base $(\mathrm{NaOH})$ at various concentrations and different material/solvent ratios for a certain time. The flask is shake at $120 \mathrm{rpm}$ with a mechanical shaker. After the pretreatment time, the solid material is collected out of the solution by filtration.

\subsection{Definition of pretreatment efficiency}

Regardless the loss of cellulose, which is not significant in the pretreatment conditions, pretreatment efficiency is defined as the percentage of lignin removed from a fixed amount of cellulose:

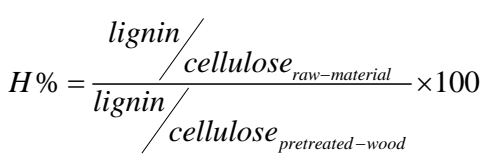

\section{Results and discussion}

\subsection{Raw material composition}

Analysis results showed that the material was mainly composed of cellulose (47.5 wt.\%), lignin (30.1 wt.\%), and the others $(22.4$ wt.\%). Acid-insoluble lignin was found of $26.3 \mathrm{wt} . \%$.

\subsection{Saw dust particle size}

It is known that the smaller size of saw dust particles, the more contact area between the solid and liquid. Alkaline pretreatment was done for saw dust with different particle size obtained through screening. The aqueous solution of $\mathrm{NaOH} 2.0$ wt.\% was employed at material/solvent ratio $1: 10$ and the reaction time of $24 \mathrm{~h}$ at room temperature. As presented in Fig. 1, the pretreatment efficiency increased with the decrease of the saw dust particle size but remained unchanged with the size less than $0.8 \mathrm{~mm}$. This result suggested the use of fine saw dust with size at maximum about $0.5 \mathrm{~mm}$.

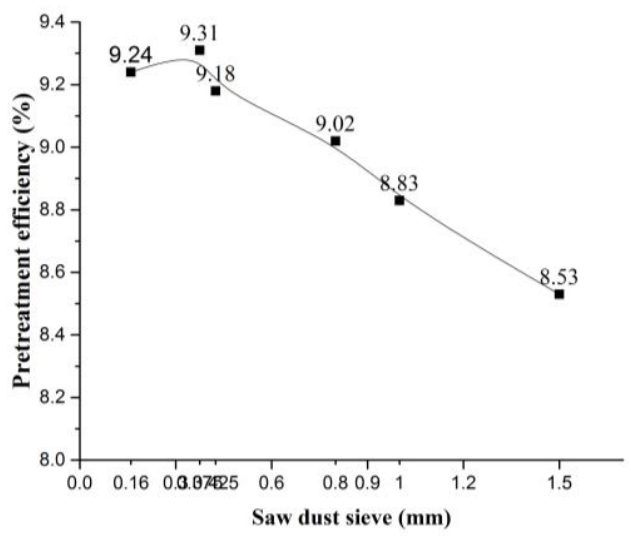

Fig. 1. The dependence of alkaline pretreatment efficiency on saw dust particle size (pretreatment conditions: $\mathrm{NaOH}$ concentration $2 \%$, material/solvent ratio $1: 10,24 \mathrm{~h}$ at room temperature). 


\subsection{Material/solvent ratios}

The effect of material/solvent ratios on the pretreatment efficiency was inspected with aqueous solutions of $\mathrm{NaOH} 2.0$ wt\% and $\mathrm{H}_{2} \mathrm{SO}_{4} 2.0$ wt.\% as shown in Fig. 2.

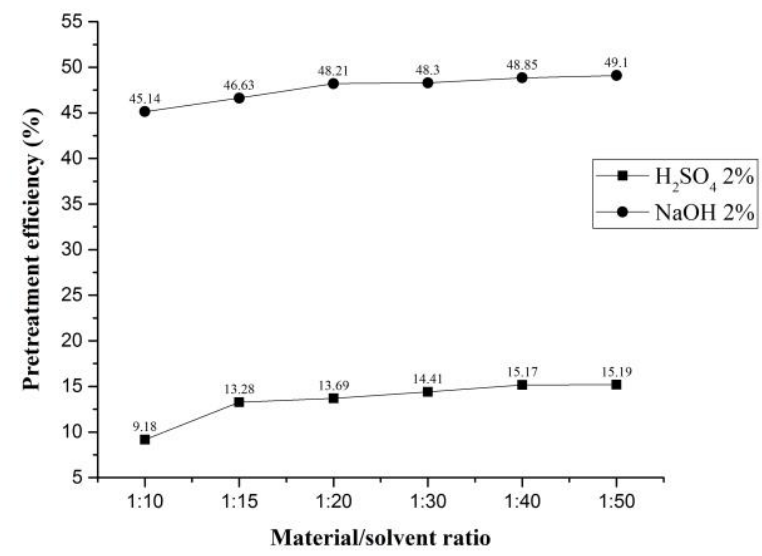

Fig. 2. Material/solvent ratio analysis

The pretreatment efficiency was ascending with the ratios as more alkali or acid is used to delignify the samples. However, the differences were not so much with alkaline pretreatment while it was observed that there would be a difficulty in mixing the mixture if the ratio of solid/liquid reduced to lower than 1:15. For further experiments, the ratio 1:20 was chosen as the optimum.

\subsection{Pretreatment agent concentrations}

As shown in Fig. 3, the optimal concentration for alkaline solution to pretreat rubber saw dust can be chosen as 2.5 wt.\% while higher concentration did not give higher pretreatment efficiency. Noticeably, with acidic pretreatment, the concentration of $\mathrm{H}_{2} \mathrm{SO}_{4}$ higher than $2.0-2.5$ wt. $\%$ gave decreasing pretreatment efficiency, which is ascribed to carbohydrate hydrolysis. To proceed further experiments, aqueous $\mathrm{H}_{2} \mathrm{SO}_{4} 2.0$ wt. $\%$ and 2.5 wt. $\% \mathrm{NaOH}$ are the pretreatment solution to choose.

\subsection{Pretreatment time}

Pretreatment time is an important factor in industrial scaled production. In general, the alkaline pretreatment is more efficient than that of acidic pretreatment in the same retention time. Presented in Fig. 4, the pretreatment efficiency increased then remained unchanged at $24 \mathrm{~h}$ (48.5\% for $\mathrm{NaOH} 2 \%$ and $13.7 \%$ for $\mathrm{H}_{2} \mathrm{SO}_{4} 2.5 \%$ ), suggesting a pretreatment time of 24 hours in these conditions is recommended.

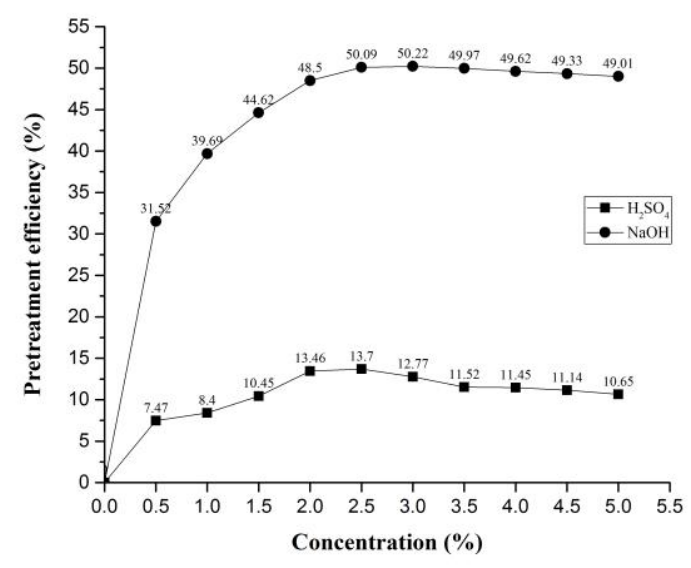

Fig. 3. The result of alkaline and acidic pretreatment at various concentrations.

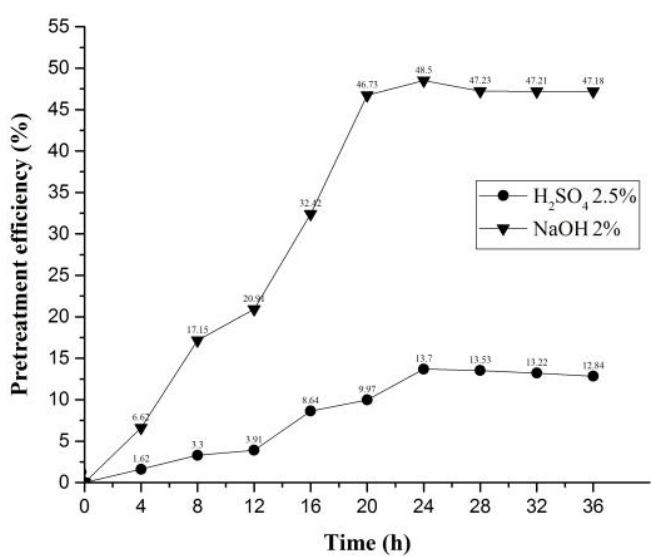

Fig. 4. The pretreatment efficiency at different times.

\subsection{Ultimate pretreatment by combining both acidic and alkaline pretreatment}

To utilize the acid for wasted alkaline solution neutralization, aqueous $\mathrm{H}_{2} \mathrm{SO}_{4} 2.5$ wt.\% was used to pretreat the saw dust before or after alkaline pretreatment. Herein, two experiments were set up as followings.

Experiment 1: Pretreatment with $\mathrm{NaOH} 2.0$ wt.\% followed by acidic pretreatment with $\mathrm{H}_{2} \mathrm{SO}_{4} 2.5 \mathrm{wt} . \%$.

Experiment 2: Pretreatment with $\mathrm{H}_{2} \mathrm{SO}_{4} 2.5$ wt.\% followed by alkaline pretreatment with $\mathrm{NaOH} 2.0$ wt.\%.

The results of these so-called combo-pretreatment were presented in Table 1 .

Table 1. The results of the pretreatment with acidic, alkaline solution, and by combo-technique.

\begin{tabular}{|l|l|l|l|l|}
\hline & $\begin{array}{c}\text { Pretreatment } \\
\text { with only } \\
\mathrm{H}_{2} \mathrm{SO}_{4} 2.5 \\
\text { wt.\% }\end{array}$ & $\begin{array}{c}\text { Pretreatment } \\
\text { with only } \\
\text { NaOH 2.0 } \\
\text { wt.\% }\end{array}$ & Exp 2 & Exp 1 \\
\hline $\begin{array}{l}\text { Pretreatment } \\
\text { efficiency (\%) }\end{array}$ & 13.7 & 48.2 & 63.0 & 26.37 \\
\hline $\begin{array}{l}\text { Final cellulose } \\
\text { content (\%) }\end{array}$ & 55.47 & 60.45 & 68.73 & 42.32 \\
\hline
\end{tabular}


Based on the experimental results in Table 1, the pretreatment efficiency in Exp. 2 by combo-technique is the highest among 4 experiments. Interestingly, combotechnique in Exp. 1 gave surprisingly low pretreatment efficiency. It can be explained that during the prior alkaline pretreatment, a large portion of lignin was removed. Thus the cellulose in the following acidic pretreatment was hydrolyzed intensively. Indeed, the final cellulose content of Exp 1 is the lowest among the 4 entries.

Compared with single pretreatment, combotechnique in Exp 2 improved the pretreatment efficiency significantly. The wasted solution of both acidic and alkaline pretreatment could be mixed finally to neutralize each other before disposal.

\section{Conclusion}

Acidic $\left(\mathrm{H}_{2} \mathrm{SO}_{4} 2.5\right.$ wt.\%) and alkaline $(\mathrm{NaOH} 2.0$ wt.\%) solutions were respectively used to pretreat rubber saw dust in a so-called combo-technique in order to increase the pretreatment efficiency. Instead of using acids only to neutralize the alkaline wasted solution, this method could increase the pretreatment efficiency from $48.2 \%$ as in the single alkaline pretreatment to $63.0 \%$. This modified process gives a positive meaning to the industrial production of the second-generation bioethanol.

This research was funded by Vietnam National University Ho Chi Minh City (VNU-HCM) under grant number B2018-20-02.

\section{References}

[1] Q. D. Nguyen, T. K. P. Le, and T. A. T. Tran, A technique to smartly-reuse alkaline solution in lignocellulose pre-treatment, Chemical Engineering Transactions 63 (2018) 157-162.

[2] J. Sheehan, The road to bioethanol: a strategic perspective of the US Department of Energy's national ethanol program, in "Glycosyl Hydrolases for Biomass Conversion" edited by M. Himmel, J. Baker, and J. Saddler, published in Washington DC by American Chemical Society (2001), 2-25.

[3] D. P. Koullas, P. Christakopoulos, D. Kekos, B. J. Macris, and E. G. Koukios, Correlating the effect of pretreatment on the enzymatic hydrolysis of straw, Biotechnol. Bioeng. 39 (1992) 113-1 16.

[4] J. Azuma, T. Asai, M. Isaka, and T. Koshijima, Effects of microwave irradiation on enzymatic susceptibility of crystalline cellulose, J. Ferment. Technol. 63 (1985) 529-536.

[5] L. P. Ramos, M. M. Nazhad, and J. N. Saddler, Effect of enzymatic hydrolysis on the morphology and fine structure of pretreated cellulosic residues, Enzyme Microb. Technol. 15 (1993) 821-831.

[6] J. Szczodrak, Z. Ilczuk, J. Rogalski, and A. Leonowicz, Intensification of oak sawdust enzymatic hydrolysis by chemical or hydrothermal pretreatment, Biorechnol. Bioeng. 28 (1986) 504510.
[7] M. A. Farid, H. M. Shaker, and A. I. El-Diwany, Effect of peracetic acid, sodium hydroxide and phosphoric acid on cellulosic materials as a pretreatment for enzymatic hydrolysis. Enzyme Microb. Technol. 5 (1983) 421424.

[8] R. S. Bes, G. Gas, J. Molinier, P. Vidal, J. Mathieu, and J. C. Mora, Enhancement of poplar cellulose susceptibility to cellulase enzyme hydrolysis by ozonation, Ozone Science Eng. 11 (1989) 217-226.

[9] C. Rolz, R. De Leon, M. C. De Arriola, and S. De Cabrera, Biodelignification of lemon grass and citronella bagasse by white-rot fungi, Appl. Environ. Microbial. 52 (1986) 607611.

[10] M. Mes-Hartree, E. K. C. Yu, I. D. Reid, and J. N. Saddler, Suitability of aspenwood biologically delignified with Phlebia rremellosus for fermentation to ethanol or butanediol, Appl. Microbial. Biotechnol. 26 (1987) 120-125.

[11] V. P. Puri and G. R. Pearce, Alkali-explosion pretreatment of straw and bagasse for enzymic hydrolysis, Biotechnol. Bioeng. 28 (1986) 480-485.

[12] H. Bateni, K. Karimi, A. Zamani, F. Benakashani, Castor plant for biodiesel, biogas, and ethanol production with a biorefinery processing perspective, Appl. Energy 136 (2014) 14-22.

[13] A.Sluiter, B.Hames, R.Ruiz, C.Scarlata, J.Sluiter, D.Templeton, D.Crocker, Determination of Ash in biomass, National Renewable Energy Laboratory (NREL) Analytical Procedures, NREL/TP-510-42622 (2008).

[14] A.Sluiter, B.Hames, R.Ruiz, C.Scarlata, J.Sluiter, D.Templeton, D.Crocker, Determination of structural carbonhidrates and lignin in biomass, National Renewable Energy Laboratory (NREL) Analytical Procedures, NREL/TP-510-42618 (2008).

[15] F.J.Viles Jr., and Leslie Silverman, Determination of Starch and Cellulose with Anthrone, in "Analytical Chemistry", published in 1949, 950-953 